\title{
Normal Clinical Outcome in Untreated Subjects with Mild Hyperphenylalaninemia
}

\author{
JOSEF WEGLAGE, MICHAEL PIETSCH, REINHOLD FELDMANN, HANS-GEORG KOCH, \\ JOHANNES ZSCHOCKE, GEORG HOFFMANN, ANJA MUNTAU-HEGER, JONAS DENECKE, \\ PER GULDBERG, FLEMMING GÜTTLER, HARALD MÖLLER, UDO WENDEL, \\ KURT ULLRICH, AND ERIK HARMS \\ Departments of Pediatrics [J.W., M.P., R.F., H.-G.K., J.D., E.H.] and Clinical Radiology [H.M.], \\ University of Münster, 48129 Münster, Germany; Department of Pediatrics, University of Heidelberg, \\ 69120 Heidelberg, Germany [J.Z., G.H.]; Department of Pediatrics, University of München, 80337 \\ München, Germany [A.M.-H.]; John F. Kennedy Institute, Glostrup, 2600 Glostrup, Denmark [P.G., \\ F.G.]; Department of Pediatrics, University of Düsseldorf, 40225 Düsseldorf, Germany [U.W.]; and \\ Department of Pediatrics, University of Hamburg, 20246 Hamburg, Germany [K.U.].
}

\begin{abstract}
ABST
There is international consensus that patients with phenylal-
anine (Phe) levels $<360 \mu \mathrm{M}$ on a free diet do not need Phe-
lowering dietary treatment whereas patients with levels $>600$
$\mu \mathrm{M}$ do. Clinical outcome of patients showing Phe levels between
360 and $600 \mu \mathrm{M}$ in serum on a free nutrition has so far only been
assessed in a small number of cases. Therefore, different recom-
mendations exist for patients with mild hyperphenylalaninemia.
We investigated in a nationwide study 31 adolescent and adult
patients who persistently displayed serum Phe levels between
360 and $600 \mu \mathrm{M}$ on a normal nutrition with a corresponding
genotype. Because of limited accuracy of measurements, Phe
levels should be looked on as an approximation, but not as an
absolute limit in every instance. In addition to serum Phe levels,
the assessment program consisted of comprehensive psycholog-
ical testing, magnetic resonance imaging of the head, ${ }^{1} \mathrm{H}$ mag-
netic resonance spectroscopy, and genotyping. We found a nor-
mal intellectual (intelligence quotient, $103 \pm 15$; range, $79-138$ )
and educational (school performance and job career) outcome in
these subjects as compared with healthy control subjects (intel-
ligence quotient, $104 \pm 11$; range, $80-135$ ). Magnetic resonance
\end{abstract}
imaging revealed no changes of cerebral white matter in any patient, and ${ }^{1} \mathrm{H}$ magnetic resonance spectroscopy revealed brain Phe levels below the limit of detection $(<200 \mu \mathrm{M})$. In the absence of any demonstrable effect, dietary treatment is unlikely to be of value in patients with mild hyperphenylalaninemia and serum Phe levels $<600 \mu \mathrm{M}$ on a free nutrition, and should no longer be recommended. Because of a possible late-onset phenylketonuria, Phe levels of untreated patients should be monitored carefully at least during the first year of life. Nevertheless, problems of maternal phenylketonuria should still be taken into account. (Pediatr Res 49: 532-536, 2001)
PKU, phenylketonuria
Abbreviations:
HPA, hyperphenylalaninemia
IQ, intelligence quotient
Phe, phenylalanine
MR, magnetic resonance
MRI, magnetic resonance imaging

PKU owing to Phe hydroxylase deficiency is one of the most common inborn errors of metabolism. Different recommendations do exist concerning the treatment (1-3). The Phe hydroxylase gene can be mapped to chromosome 12q22-q24.1 $(4,5)$. Up to now, $>400$ different mutant Phe hydroxylase alleles have been described (4).

Received February 24, 2000; accepted November 25, 2000.

Correspondence and reprint requests: Josef Weglage, M.D., Ph.D., Department of Pediatrics, University of Münster, Albert-Schweitzer-Str. 33, D-48129 Münster, Germany; e-mail: weglage@uni-muenster.de

Supported by the SHS Company, Heilbronn, Germany, and the Arbeitsgemeinschaft für Pädiatrische Stoffwechselerkrankungen (APS).
On the basis of the serum Phe levels on a free nutrition, patients with HPA are classified as classic PKU $(>1200 \mu \mathrm{M})$, mild PKU $(600-1200 \mu \mathrm{M})$, or mild HPA $(<600 \mu \mathrm{M})(2,6)$. The classification limits are historic. There is international consensus that patients with Phe levels $<360 \mu \mathrm{M}$ on a free diet are not in need of a Phe-lowering dietary treatment, whereas patients with levels $>600 \mu \mathrm{M}$ are. Different recommendations exist for patients with Phe levels between 360 and $600 \mu \mathrm{M}$ on a free nutrition.

In spite of early and adequate dietary treatment, patients with mild or classic PKU show a mild reduction of IQ (7-9), abnormalities of cerebral white matter $(10,11)$, and deficits of fine motor performances (12) and sustained and selective 
attention $(13,14)$, as well as impaired executive functions depending on (pre)frontal lobe functions $(15,16)$. The latter may be the consequence of a central dopamine depletion. In addition, neurologic deterioration was described in some adult patients who stopped their diet for more than $10 \mathrm{y}$ (17).

The authors of a study from Great Britain $(1,18)$ in which the IQ was measured concluded that all patients with Phe levels $>360 \mu \mathrm{M}$ on a normal diet should be treated. In their study they included patients with Phe levels $<900 \mu \mathrm{M}$. Most German patients with mild HPA are not treated, as a normal outcome was anticipated $(2,3)$.

In 1997 we performed a first systematic study and found normal intellectual, neurologic, and neuropsychological outcomes in 28 untreated subjects with mild HPA compared with healthy control individuals (3). However, in that study only 10 of 28 patients had Phe levels in the controversial range between 360 and $600 \mu \mathrm{M}$ on a free nutrition. Our results were supported by findings of Levy et al. (19), who reported normal IQs in 13 4-y-old patients with mild HPA and who were comparable to the IQs of their unaffected siblings. In another study by Levy and Waisbren (20), eight women with mild HPA reached a normal mean IQ. In a study on maternal mild HPA, Levy et al. (21) found a normal median IQ of 105 in 37 of 86 women for whom IQ test results were available. Patients with Phe levels $<400 \mu \mathrm{M}$ had a higher median IQ (108) compared with patients with Phe levels above this level (100), but this difference was not significant (21). Waisbren et al. (22) found no intellectual deficits or abnormalities in personality in a group of 12 patients with untreated PKU $(n=6)$ and mild HPA $(n=6)$. Unfortunately no data were published on the socioeconomic status of the patients in these studies.

To overcome the limitation of our first study, we now investigated in a nationwide study adolescent and adult patients with mild HPA and Phe levels within the critical range between 360 and $600 \mu \mathrm{M}$ on a normal nutrition. The hypothesis tested was that untreated subjects with mild HPA and Phe levels on a free nutrition between 360 and $600 \mu \mathrm{M}$ are not at risk for developing intellectual, neurologic, and neuropsychological deficits.

\section{METHODS}

Subjects. All departments of pediatrics of the 22 German University Hospitals were involved in this study. Four hospitals had no patients with mild HPA and Phe levels between 360 and $600 \mu \mathrm{M}$ on a free diet, whereas at six hospitals these patients were treated with a Phe-restricted diet. At 12 hospitals there were altogether 40 patients with untreated mild HPA $>10$ $\mathrm{y}$ of age. Thirty-one of these 40 patients were willing and able to take part in our study (Table 1), five patients were not available, and four patients did not consent to participate because they expected no benefit for themselves. These patients did not significantly differ from the participating subjects in socioeconomic status and school career (information by telephone).

Healthy control subjects (friends of patients) were selected according to age, sex, and socioeconomic status. Informed consent was obtained from all patients and healthy control
Table 1. Description of study groups

\begin{tabular}{lcc}
\hline Variable & Mild HPA $(n=31)$ & Control $(n=31)$ \\
\hline Age & $19.1 \pm 8.1(11-30)$ & $19.3 \pm 7.2(11-30)$ \\
median, 18 & median, 18 \\
Sex & 16 female, 15 male & 16 female, 15 male \\
SES & & \\
High & 0 & 0 \\
Middle-high & 5 & 5 \\
Middle & 15 & 15 \\
Middle-low & 9 & 9 \\
Low & 2 & 2 \\
\hline
\end{tabular}

Abbreviation: SES, socioeconomic status.

subjects and their parents. The study was approved by the Ethics Committee of the University of Münster. Patients with mild HPA were defined by serum Phe levels persistently between 360 and $600 \mu \mathrm{M}$ in the neonatal screening test and sporadic tests throughout life, as well as four determinations at 2-wk intervals during the study (mean study levels; Table 2). Serum Phe levels during the study were measured by amino acid analyzer (HPLC). Blood samples were taken $4-5 \mathrm{~h}$ after the last meal. For 29 patients, Phe levels of the neonatal screening test (first quantitative measurement within $1 \mathrm{wk}$ after the Guthrie test, $n=22$ ) or Guthrie bacterial inhibition assay for Phe $(n=29)$ were available.

One older patient included in the sample was born before the general screening program was introduced, and for one patient the result of the screening test was not available. Four patients were characterized by a Blascovics Phe load at the age of 4-6 mo (23). A mean lifetime serum Phe level was not computed because Phe checks were performed only sporadically. Socioeconomic status was defined with the help of the variables family income, academic qualification, and job of the father as described earlier (3). Concerning school and job career, we obtained informations of altogether 31 patients and their siblings by asking their parents.

Mutation analysis. All 13 exons and flanking intronic sequences of the Phe hydroxylase gene from 30 non-PKU HPA subjects were amplified by PCR and scanned for the presence of mutations by denaturant grading gel electrophoresis according to previously described procedures (24). All samples displaying an altered electrophoretic band pattern were subjected to direct sequencing. In general, genotyping may help to categorize the patients as mild HPA at an early stage of life.

Assessment procedures. The assessment program consisted of tests that had previously revealed significant deficits in patients with classic or mild PKU who were treated early

Table 2. Serum phenylalanine levels

\begin{tabular}{lllll}
\hline & \multicolumn{4}{c}{ Phenylalanine $(\mu \mathrm{M})$} \\
\cline { 2 - 5 } Variable & Mean & SD & Range & Median \\
\hline Whole sample $(n=31)$ & & & & \\
$\quad$ Neonatal screening $(n=22)$ & 467 & 150 & $360-606$ & 480 \\
$\quad$ Mean study level & 452 & 120 & $360-600$ & 438 \\
MRI $/{ }^{1}$ H-spectroscopy group $(n=10)$ & & & & \\
$\quad$ Neonatal screening & 430 & 130 & $390-580$ & 420 \\
$\quad$ Mean study level & 440 & 110 & $380-560$ & 430 \\
\hline
\end{tabular}


(7-14). These tests had already been used in our recent study on patients with mild HPA (3), where they are described in detail. Patients and controls were examined for clinicalneurologic outcome, IQ [German version of Wechsler intelligence scale for adults - revised and Wechsler intelligence scale for children-revised; $(25,26)]$, school performance and job career, selective attention [Color Word Interference Task = Stroop task; (27)], and sustained attention [dot pattern exercise from the Sonneville Visual Attention Task; (28)], as well as for their fine motor performances [Motor Performance Task; (29)]. In addition, cranial MRI and ${ }^{1} \mathrm{H}$ MR spectroscopy were obtained in 10 patients using a superconducting $1.5-\mathrm{T}$ magnet (Magneton, Siemens) using spin-echo pulse sequences. $\mathrm{T}_{1^{-}}$ weighted and proton density-weighted images [transmission time (TR), 2500; echo time (TE) 15/90] were acquired in the axial plane. In addition coronal $\mathrm{T}_{2}$-weighted images (TR 600 , TE 1.5) were obtained. Brain Phe concentrations were determined by localized ${ }^{1} \mathrm{H}$ spectroscopy applying the STEAM technique on a 1.5-T MR unit (Siemens, Germany) in 10 patients. Spectra were recorded from periventricular occipital brain as described previously [TR/TE, 1500/20 ms; 512 acquisitions; $36-\mathrm{mL}$ voxels; (30)]. The 10 patients had mean study Phe levels of $440 \pm 110 \mu \mathrm{M}$.

Data analysis. Nonparametric tests (Wilcoxon test, correlation according to Spearman, $\chi^{2}$ test) were used for statistical evaluation.

\section{RESULTS}

Genotypes and corresponding biochemical phenotypes. The present investigation supports previous suggestions that mild HPA is caused in most cases by compound heterozygosity for a PKU mutation and mild HPA mutation (5) (Table 3).

Clinical-neurologic outcome. Clinical-neurologic examination revealed mild rest and intention tremor in one subject with mild HPA and clumsy diadochokinesis in a control subject. Physical development was normal in all subjects with mild HPA and in all healthy control subjects.

Intelligence. The 31 subjects with mild HPA attained a mean IQ within the normal range. Verbal IQ and performance IQ did not significantly differ (Table 4).

School performance. The 31 patients, their 31 siblings, and the 31 healthy control subjects did not significantly differ with regard to age at start of schooling, types of schools, and repetition of classes (Table 5).

Job career. Patients and siblings, as well as healthy control subjects, did not significantly differ with respect to their jobs (Table 6).

Sustained attention. Levels of performance as well as the stability of performance on the dot pattern exercises of Sonneville Visual Attention Task were not significantly different for subjects with mild HPA and healthy control subjects (Table 7).

Selective attention. The Color Word Interference Task, which depends on frontal lobe functions, revealed no significant difference between subjects with mild HPA and control subjects (Table 8).
Table 3. Genotypes and serum phenylalanine levels of 31 patients

\begin{tabular}{|c|c|c|c|}
\hline \multirow{2}{*}{$\begin{array}{l}\text { Allele I: } \\
\text { mild } \\
\text { HPA } \\
\text { mutation }\end{array}$} & \multirow[b]{2}{*}{$\begin{array}{c}\text { Allele II: PKU } \\
\text { mutation }\end{array}$} & \multicolumn{2}{|c|}{ Serum Phe levels } \\
\hline & & $\begin{array}{c}\text { Screening } \\
(\mu \mathrm{M})\end{array}$ & $\begin{array}{c}\text { Mean study level } \\
(\mu \mathrm{M})\end{array}$ \\
\hline $165 \mathrm{~V}$ & IVS12nt1 & $360 \dagger$ & 390 \\
\hline $165 \mathrm{~V}$ & IVS12nt1 & 372 & 393 \\
\hline S78R & P281L & 410 & 366 \\
\hline E178G & G272X & 396 & 462 \\
\hline E178G & R261Q & 468 & 408 \\
\hline V245A & P281L & 492 & 558 \\
\hline $\mathrm{A} 300 \mathrm{~S}$ & IVS12nt1 & -------- & 460 \\
\hline $\mathrm{I} 306 \mathrm{~V}$ & IVS12nt1 & $360 \dagger$ & 380 \\
\hline $\mathrm{I} 306 \mathrm{~V}$ & R408W & 594 & 462 \\
\hline E390G & $\mathrm{R} 243 \mathrm{X}$ & 450 & 498 \\
\hline E390G & $\mathrm{R} 243 \mathrm{X}$ & 510 & 570 \\
\hline E390G & $\mathrm{R} 158 \mathrm{Q}$ & $420 \dagger$ & 408 \\
\hline E390G & Q20X & $360 \dagger$ & 438 \\
\hline E390G & G272X & 606 & 432 \\
\hline E390G & G272X & 580 & 408 \\
\hline E390G & IVS12nt & 480 & 408 \\
\hline E390G & R408W & 426 & 517 \\
\hline E390G & R408W & 402 & 436 \\
\hline E390G & ------- & 390 & 398 \\
\hline E390G & --------- & $420 \dagger$ & 422 \\
\hline A403V & R408W & 390 & 408 \\
\hline A403V & IVS12nt1 & ----- & 360 \\
\hline A403V & IVS12nt1G $>A$ & $600 \dagger$ & 510 \\
\hline A403V & $\mathrm{K} 341 \mathrm{X}$ & 562 & 462 \\
\hline A403V & -------- & 599 & 396 \\
\hline D415N & -------- & 450 & 600 \\
\hline Y414C* & L48S* & 360 & 516 \\
\hline Y414C* & L48S* & 599 & 492 \\
\hline Y414C* & Y414C* & 480 & 462 \\
\hline -------- & --------- & 570 & 402 \\
\hline --------- & --------- & $480 \dagger$ & 588 \\
\hline
\end{tabular}

* PKU mutation (4). $\uparrow$ Screening test results by Guthrie bacterial inhibition assay only.

--- Mutation not discovered.

Fine motor performance. The Motor Performance Task revealed no significant fine motor deficits in patients with mild HPA (Table 9).

MRI. The blinded evaluation of patients' scans revealed no abnormalities in any case, especially no alterations of cerebral white matter.

${ }^{1} \boldsymbol{H}$ MR spectroscopy. In all patients brain Phe concentrations were below the limit of detection $(<200 \mu \mathrm{M})$.

Correlational findings. The Phe levels of the screening test and the mean study levels were significantly correlated $(r=$ $0.57, p<0.001)$. Correlational analysis according to Spearman revealed no significant relation between serum Pe levels (screening test and mean study level) and results of psychological measures.

\section{DISCUSSION}

Data presented confirm the results of our recent study on patients with mild HPA (3). Adolescent and adult patients with mild HPA and serum Phe levels in the disputed range of 360 to $600 \mu \mathrm{M}$ seem to be not at risk for developing significant intellectual, neurologic, and neuropsychologic 
Table 4. Intelligence score

\begin{tabular}{|c|c|c|c|c|c|c|c|c|}
\hline \multirow[b]{2}{*}{ IQ } & \multicolumn{4}{|c|}{ Mild HPA $(n=31)$} & \multicolumn{4}{|c|}{ Control $(n=31)$} \\
\hline & Mean & $\mathrm{SD}$ & Range & Median & Mean & $\mathrm{SD}$ & Range & Median \\
\hline General & 103 & 15 & $79-138$ & 102 & 104 & 11 & $80-135$ & 105 \\
\hline Verbal & 103 & 16 & $76-135$ & 100 & 103 & 15 & $76-135$ & 102 \\
\hline Performance & 102 & 14 & $79-139$ & 102 & 105 & 14 & $83-133$ & 104 \\
\hline
\end{tabular}

Differences between groups were not significant by one-sided Wilcoxon test.

Table 5. School performance

\begin{tabular}{lccc}
\hline \multicolumn{1}{c}{ School } & Mild HPA $(n=31)$ & Sibling $(n=31)$ & Control $(n=31)$ \\
\hline Age at starting school (y)* & $6.3 \pm 0.5$ & $6.2 \pm 0.4$ & $6.3 \pm 0.6$ \\
median, 6 & 24 & 21 \\
Repeated classes (\%) & median, 6 & & 21 \\
Type of schools attended (\%) $\dagger$ & 24 & 38 & 41 \\
Elementary school (Hauptschule) & & 38 & 41 \\
High school (Realschule) & 14 & 3 & 0 \\
College (Gymnasium) & 41 & 38 & \\
Special school for disabled & 7 & & \\
children (Sonderschule) & & & \\
\hline
\end{tabular}

* Not significant by ANOVA.

$\uparrow$ No significant difference by $\chi^{2}$ test.

Table 6. Job career

\begin{tabular}{lcrr}
\hline \multicolumn{1}{c}{ Variable } & Mild HPA $(n=31)$ & Sibling $(n=31)$ & Control $(n=31)$ \\
\hline Still at school (\%) & 24 & 24 & 21 \\
Job without training (\%) & 7 & 7 & 3 \\
Job with training (\%) & 57 & 55 & 64 \\
Academic education (\%) & 12 & 14 & 12 \\
\hline
\end{tabular}

No significant difference by $\chi^{2}$ test.

Table 7. Sustained attention dot pattern exercise

\begin{tabular}{|c|c|c|c|c|c|c|}
\hline Variable & \multicolumn{3}{|c|}{ Mild HPA $(n=31)$} & \multicolumn{3}{|c|}{ Control $(n=31)$} \\
\hline \multicolumn{7}{|l|}{ Correct answers } \\
\hline 5 dots & 196 & 3.2 & 197 & 195 & 3.7 & 194 \\
\hline 4 dots & 185 & 10.4 & 184 & 186 & 10.2 & 187 \\
\hline \multicolumn{7}{|l|}{ Reaction times (ms) } \\
\hline 4 dots & 730 & 199 & 738 & 702 & 160 & 708 \\
\hline \multicolumn{7}{|c|}{ Mean reaction time of 50 series (s) } \\
\hline & 8.8 & 1.9 & 8.7 & 9.1 & 2.5 & 9.1 \\
\hline
\end{tabular}

All one-sided Wilcoxon test results were not significant.

deficits or abnormalities of cerebral white matter, as described for patients with mild or classic PKU (7-14). Because of the limited accuracy of measurements, Phe levels should be taken as an approximation but not as absolute limits in every instance.

Our results are supported by findings of Levy et al. (19), Levy and Waisbren (20), Levy et al. (21), and Waisbren et al. (22). The discrepancy between the IQ data of the present study and the study from Great Britain are possibly related to the inclusion of patients with Phe levels between 600 and $900 \mu \mathrm{M}$ in the British sample (1).

In the present study, as in our previous study on mild HPA (3), results of different tests were not significantly correlated with Phe levels (neonatal screening as well as mean study levels).
In conclusion, in the absence of any effect on clinical outcome, treatment is unlikely to be of benefit to subjects with mild HPA and serum Phe levels $<600 \mu \mathrm{M}$ on free nutrition. In addition brain Phe levels $<200 \mu \mathrm{M}$ seem to allow a normal cognitive development. Our results support the recommendations of the German Working Group for Metabolic Diseases from 1999, supposing that only patients with HPA caused by phenylalanine hydroxylase (PAH) deficiency and serum Phe levels of $\geq 600 \mu \mathrm{M}$ on a free nutrition must be treated (2). Because of a possible late-onset PKU, untreated patients should be monitored very carefully at least during the first year of life (4). Further studies are needed to clarify whether 600 $\mu \mathrm{M}$ is the exact limit for this treatment decision. A very burdensome, stigmatizing, and expensive dietary treatment should be avoided. 
Table 8. Selective attention (Color Word Interference Task, Stroop task)

\begin{tabular}{|c|c|c|c|c|c|c|}
\hline \multirow[b]{2}{*}{ Variable } & \multicolumn{3}{|c|}{ Mild HPA $(n=31)$} & \multicolumn{3}{|c|}{ Control $(n=31)$} \\
\hline & Mean & SD & Median & Mean & SD & Median \\
\hline Color word reading $\dagger$ & 55 & 8 & 55 & 54 & 8 & 53 \\
\hline Interference task $\dagger$ & 54 & 8 & 54 & 55 & 8 & 53 \\
\hline Nomination $\dagger$ & 49 & 10 & 50 & 52 & 10 & 51 \\
\hline Selectivity $\dagger$ & 53 & 8 & 54 & 52 & 9 & 53 \\
\hline
\end{tabular}

All one-sided Wilcoxon test results were not significant.

* Number of mistakes (untransformed, $t$ values do not exist).

$\dagger$ Data given as $t$ values.

Table 9. Motor performance task-dominant right hand

\begin{tabular}{|c|c|c|c|c|}
\hline \multirow[b]{2}{*}{ Task } & \multicolumn{2}{|c|}{ Mild HPA $(n=31)$} & \multicolumn{2}{|c|}{ Control $(n=31)$} \\
\hline & Mean & $\mathrm{SD}$ & Mean & $\mathrm{SD}$ \\
\hline \multicolumn{5}{|c|}{ Steadiness } \\
\hline $\mathrm{F}$ & 0.1 & 1.3 & -0.1 & 0.5 \\
\hline FD & 0.1 & 1.2 & -0.1 & 0.5 \\
\hline \multicolumn{5}{|c|}{ Follow lines } \\
\hline $\mathrm{F}$ & 0.2 & 1.0 & -0.2 & 0.9 \\
\hline FD & 0.2 & 1.2 & -0.2 & 1.2 \\
\hline GD & -0.1 & 1.0 & 0.1 & 0.9 \\
\hline \multicolumn{5}{|l|}{ Aiming } \\
\hline $\mathrm{F}$ & 0.2 & 1.2 & -0.2 & 0.9 \\
\hline FD & 0.1 & 1.2 & -0.1 & 0.8 \\
\hline TR & -0.1 & 1.1 & 0.1 & 0.6 \\
\hline GD & -0.2 & 1.3 & 0.2 & 0.9 \\
\hline \multicolumn{5}{|l|}{ Long pins } \\
\hline GD & 0.1 & 1.3 & -0.1 & -0.9 \\
\hline \multicolumn{5}{|l|}{ Tapping } \\
\hline TR & -0.2 & 1.1 & 0.2 & -0.3 \\
\hline \multicolumn{5}{|l|}{ Rotor } \\
\hline $\mathrm{F}$ & 0.1 & 1.0 & -0.1 & -0.9 \\
\hline FD & 0.1 & 1.2 & -0.1 & 1.1 \\
\hline
\end{tabular}

All one-sided Wilcoxon test results were not significant.

Abbreviations: F, number of mistakes; FD, mean period of mistakes; GD, whole time of a task; TR, number of hits.

Nevertheless, problems of maternal PKU should be intensively discussed with women with mild HPA and their relatives, as their elevated serum Phe levels during pregnancy may be associated with damage to the fetus $(4,21)$.

Acknowledgment. The authors thank all patients and controls, their doctors, and dieticians for participating in this study.

\section{REFERENCES}

1. Costello PM, Beasley MG, Tillotson SL, Smith I 1994 Intelligence in mild atypical phenylketonuria. Eur J Pediatr 153:260-263

2. Burgard P, Bremer HJ, Bührdel P, Clemens PC, Mönch E, Przyrembel H, Trefz FK, Ullrich K 1999 Rationale for the German recommendations for phenylalanine leve control in phenylketonuria 1997. Eur J Pediatr 158:46-54

3. Weglage J, Ullrich K, Pietsch M, Fünders B, Güttler F, Harms E 1997 Intellectual, neurologic, and neuropsychologic outcome in untreated subjects with nonphenylketonuria hyperphenylalaninemia. Pediatr Res 42: 378-384

4. Scriver CR, Kaufman S, Eisensmith RC, Woo SLC 1995 The hyperphenylalaninemias. In: Scriver CR, Baudet AL, Sly WS, Valle D (eds) The Metabolic and Molecular Bases of Inherited Diseases, Vol I, 7th Ed. McGraw Hill, New York, pp $1015-1075$

5. Güttler F 1980 Hyperphenylalaninemia: diagnosis and classification of the various types of phenylalanine hydroxylase deficiency in childhood. Acta Paediatr Scand 280:1-80
6. Okano Y, Eisensmith RC, Güttler F, Lichter-Konecki U, Lou H, Woo SCL 1991 Molecular basis of phenotypic heterogeneity in phenylketonuria. N Engl J Med 324:1232-1238

7. Burgard P, Schmidt E, Rupp A, Schneider W, Bremer HJ 1996 Intellectual development of the patients of the German Collaborative Study of children treated for phenylketonuria. Eur J Pediatr 155(Suppl 1):33-38

8. Holtzman NA, Kornmal RA, van Doornick W, Azen C, Koch R 1986 Effect of age at loss of dietary control on intellectual performance and behavior of children with phenylketonuria. N Engl J Med 314:593-608

9. Smith I, Beasley MG, Ades AE 1990 Intelligence and quality of dietary treatment in phenylketonuria. Arch Dis Child 65:472-478

10. Thompson AJ, Tillotson S, Smith I, Kendall B, Moore SG, Brenton DP 1993 Brain MRI changes in phenylketonuria. Brain 116:811-821

11. Ullrich K, Möller H, Weglage J, Schuierer G, Bick U, LudolphA, Hahn-Ullrich H 1994 White matter abnormalities in phenylketonuria: results of magnetic resonance measurements. Acta Paediatr Suppl 407:78-82

12. Weglage J, Ullrich K, Pietsch M, Fünders B, Zaß R, Koch HG 1995 Neurological findings in early treated phenylketonuria. Acta Paediatr 84:411-415

13. Schmidt E, Rupp A, Burgard P, Pietz J, Weglage J, de Sonneville L 1994 Sustained attention in adult phenylketonuria: the influence of the concurrent phenylalanine blood level. J Clin Exp Neuropsychol 16:681-688

14. Weglage J, Pietsch M, Fünders B, Koch HG, Ullrich K 1996 Deficits in selective and sustained attention processes in early treated phenylketonurics: result of impaired frontal lobe functions? Eur J Pediatr 155:200-204

15. Diamond A 1994 Phenylalanine levels between 6 and $10 \mathrm{mg} / \mathrm{dL}$ may not be as benign as once thought. Acta Paediatr Suppl 407:89-91

16. Welsh MC, Pennington BF, Ozonhoff S, Rouse B, McCabe ERB 1990 Neuropsychology of early treated phenylketonuria: specific executive function deficits. Child Dev 61:1697-1713

17. Thompson AJ, Smith I, Brenton D, Youl BD, Rylance G, Davidson DC 1990 Neurological deterioration in young adults with phenylketonuria. Lancet 336:602605

18. Medical Research Council Working Party on Phenylketonuria 1993 Recommendations on the dietary managements of phenylketonuria. Arch Dis Child 68:426-427

19. Levy HL, Shih VE, Karolkewicz V, French WA, Carr JR, Cass V 1971 Persistent mild hyperphenylalaninemia in the untreated state: a prospective study. N Engl J Med 285:424-429

20. Levy HL, Waisbren SE 1983 Effects of untreated maternal phenylketonuria and hyperphenylalaninemia on the fetus. N Engl J Med 309:1269-1274

21. Levy HL, Waisbren SE, Lobbregt D, Allred E, Schuler A, Trefz FK 1994 Materna mild hyperphenylalaninemia: an international survey of offspring outcome. Lancet 344:1589-1594

22. Waisbren SE, Schnell R, Levy HL 1984 Intelligence and personality characteristics in adults with untreated atypical phenylketonuria and mild hyperphenylalaninemia J Pediatr 105:955-958

23. Blascovics ME, Scheffler GE, Hack S 1974 Phenylketonuria: differential diagnosis. Arch Dis Child 49:835-843

24. Guldberg P, Henriksen KF, Güttler F 1993 Molecular analysis of phenylketonuria in Denmark: $99 \%$ of the mutations detected by denaturating gradient gel electrophoresis. Genomics 17:141-146

25. Tewes U 1991 Hamburg Wechsler Intelligenztest für Erwachsene (HAWIE-R). Verlag Hans Huber, Toronto, pp 1-121

26. Tewes U 1983 Hamburg Wechsler Intelligenztest für Kinder (HAWIK-R). Verlag Hans Huber, Toronto, pp. 1-139

27. Bäumler G 1985 Farbe Wort Interferenztest (FWIT nach JR Stroop). Verlag für Posychologie, Göttingen, pp 1-93

28. Sonneville de L 1993 SVAT: a computer based approach to development and disorders of information processing. In: Maarse FJ, Akerman AE, Brand N, Mulder LJM, Van der Stelt M (eds) Computers in Psychology. Tools for Experimental and Applied Psychology. Swets and Zeitlinger, Lisse, The Netherlands, pp 268-276

29. Schoppe KJ 1974 Das MLS-Gerät: ein neuer Testapparat zur Messung feinmotorischer Leistungen. Diagnostica 20:43-46

30. Möller HE, Weglage J, Wiedermann D, Ullrich K 1998 Blood-brain barrier phenylalanine transport and individual vulnerability in phenylketonuria. J Cereb Blood Flow Metab 18:1184-1191 